\title{
FACTORS AFFECTING THE AFFECTIVE IDENTITY-MOTIVATION TO LEAD (AI-MTL) OF LECTURERS: CASE STUDY IN X UNIVERSITY
}

\author{
Immanuel Yosua, Hana Panggabean \\ Faculty of Psychology, Universitas Katolik Indonesia Atma Jaya, \\ Jl. Sudirman 51, Jakarta, Indonesia, 12930 \\ immanuel.yosua@atmajaya.ac.id.
}

\begin{abstract}
This study aims to explore the effect of Leadership Self-Efficacy (LSE), Past Leadership Experience (PLE), Organizational Identification (OI), and Perceived Job Stress as an Academic Leader (PJSAL) on Affective Identity-Motivation to Lead (AI-MTL) of lecturers at the X University simultaneously. This study also aims to explore the role of LSE in mediating relationship between PLE and AI-MTL as well as between PJSAL and AIMTL. A total of $125 \mathrm{X}$ University lecturers participated in this study (male: 53, female: 72; age range between 26-71 years old), with data collected through an online questionnaire. Data analysis then was performed using the Hierarchical Multiple Regression and Mediation Analysis. The result shows that there is a simultaneous effect of LSE, PLE, OI, and PJSAL, in predicting AI-MTL of lecturers at the X University, $F(4,120)=63.520, p<.001$. All variables can explain $67.9 \%$ of the AI-MTL variation, $R^{2}=.679$. Meanwhile, PJSAL does not provide any meaningful contribution to the AI-MTL variation. In addition, this study also confirms the role of LSE in mediating the relationship between PLE and AI-MTL partially, $c^{\prime}=1.0508, p<.001$, and fully mediating the relationship between PJSAL and AI-MTL, $c^{\prime}=-.006, p>.05$. These results emphasize the strong need to identify talents by using those factors, especially when universities have difficulty in finding their prospective leaders.
\end{abstract}

Keywords: leadership self-efficacy; past leadership experience; organizational identification; perceived job stress as an academic leader; affective-identity motivation to lead

\section{INTRODUCTION}

One of the main challenges faced by universities today is finding lecturers who are willing to become leaders (Waggoner, 2016). In the United States, Luna (2012) revealed that fewer candidates have the qualifications and are willing to be nominated as university leaders than in the past. Loomes et al. (2019) have also found the similar phenomenon in the context of Australian colleges. Although having a position at a higher education institution (e.g., as head of a department) is considered prestigious (Gmelch, 2015), lecturers are reluctant to fill in that position (DeZure et al., 2014). Several reasons that make lecturers less interested to lead in higher education, such as perceived managerial responsibilities as increasingly complex (DeZure et al., 2014) and the lack of preparation provided for the lecturers who hold managerial positions (Gmelch, 2015).
The difficulty in finding lecturers to become university leaders is also occurred in Indonesia, specifically in the X University, according to $\mathrm{M}$ as the Head of People Development and Human Resources Information System Division of the $\mathrm{X}$ University Human Resources Bureau (M, personal communication, 2019). Based on the interview results conducted with lecturers at the X University, either who are currently serving or have served before or who say no willingness in serving, two leading issues are found both at the organizational and individual levels. At the organizational level, the policy of appointing lecturers as leaders by requiring certain academic positions or academic degrees, causes the number of candidates to be very limited. This is in line with the views of Magrane et al. (2018), who see that the process of appointment as a higher education leader traditionally still relies heavily on the scholarly credibility. 
At the individual level, several issues arise related to these difficulties, which include: (1) the desire of lecturers to pursue an academic careers; (2) lecturers' perceptions of the heavier demands of either being a university leader or pursuing a career as a professor, thus making lecturers to be more focused on pursuing professorship only; and (3) lecturers' perceptions regarding the lack of support for lecturers who hold leadership positions both in the form of leadership preparation and facilities support (administrative, career management, etc.). This issue is even more interesting to be investigated because lecturers have a distinctive nature of work as professionals, that differentiates them from employees in general (Peraturan Perusahaan Yayasan X, 2019). Lecturers as professionals have high autonomy in carrying out their duties (Lockwood, 1985, as cited in Mainardes et al., 2011). Other roles such as being in leadership positions are additional only if they are willing to do so (Magrane et al., 2018).

The implementation of succession planning is expected by the X University Foundation to target that phenomenon. Succession planning is believed to be a solution to prepare for the organizational leadership sustainability (Luna, 2012; Magrane et al., 2018) although this strategy is not well known in universities in general (Gmelch, 2015). One of the constructs that the researchers deem appropriate to mapping the talent pool as the first step in succession planning is Motivation to Lead (MTL). MTL can be associated with a leader's emergence (Bergner et al., 2018) as well as being an important thing to be identified when organizations want to find out who within the organization is most interested in taking on the leadership role (Badura et al., 2020). This clarifies the urgency of MTL identification in this study.

Chan \& Drasgow (2001) have explained MTL as an individual differences construct that affect someone's decision either to participate in leadership training or take on a leadership roles and responsibilities, as well as influences his/her efforts to lead persistently.
The MTL consists of three components, namely:

(1) Affective Identity-Motivation to Lead (AI-MTL). This component describes someone who is motivated to lead because of he/she has an inner motivation that gets satisfaction from being a leader.

(2) Social Normative-Motivation to Lead (SN-MTL). This component describes someone who is motivated to lead for social normative reasons in response to the societal expectations.

(3) Noncalculative-Motivation to Lead (NCMTL). This component describes someone who is motivated to lead because he/she rarely puts into account the cost and benefit consideration of the leadership role.

In this study, the researchers want to be more focused on measuring Affective IdentityMotivation to Lead (AI-MTL) as has been carried out in several previous studies (Bergner et al., 2018; Guillen et al., 2015; Stiehl et al., 2015). This because AI-MTL is an intrinsic motivation to lead (Chan \& Drasgow, 2001). People with high AI-MTL are motivated to lead because they enjoy the leadership role (Chan \& Drasgow, 2001). In addition, previous studies have indicated AIMTL as the strongest predictor of leadership potential (Chan \& Drasgow, 2001) and leadership intention (Chan et al., 2013) compared with the other two components.

\section{Influence of leadership self-efficacy, past leadership experiences, organizational identification, and perceived job stress as an academic leader, on the AI-MTL}

Several factors are known to influence AIMTL, which include Leadership SelfEfficacy/LSE (Chan \& Drasgow, 2001; Chen, 2016) and Past Leadership Experiences/PLE (Chan \& Drasgow, 2001). LSE is a belief that someone has regarding to his/her leadership capabilities that will be able to make him/her persevere in fulfilling the leadership demands (Guillen et al., 2015; Murphy \& Johnson, 2016). LSE is believed to influence AI-MTL because someone who is more confident with 
his/her leadership abilities will be more motivated to take leadership roles than those who are less confident (Mascia et al., 2014). Past Leadership Experiences are also believed to boost someone's leadership skills (Bergner et al., 2018). Previous leadership roles are believed to form person's self-image as a leader and thus motivate him/her to take on a similar role in the future (Amit et al., 2009).

Considering Chan and Drasgow's (2001) suggestion regarding the need to pay attention to organizational context in MTL, the researchers add two other factors that allegedly will also affect AI-MTL. These two factors are consisting of Organizational Identification (OI) and Perceived Job Stress as an Academic Leader (PJASL). The results of preliminary investigations, for example, indicate the role of organizational identification to predict AI-MTL. Organizational identification defined as to what extent a person identifies him/herself with the organization, has been proven to motivate him/her to behave in a beneficial way according to the organizational needs, including by becoming a leader (Fritz \& van Knippenberg, 2017). This is also in line with the study result of DeZure et al. (2014), who have found that many lecturers are finally willing to lead because they see it as a form of service or dedication towards the organization.

Furthermore, the same initial investigations indicate the possibility of negative perceptions of lecturers (both related to the managerial duties and the lack of organizational support) to affect their desire to take office. Porter et al. (2016) believed that one's view on whether the leadership environment can be supportive while leading and the implications one might experience during a leadership tenure, determine whether a leadership responsibility will be taken or not. In this case, if a leadership responsibility is seen as causing work stress, then the leadership role tends not to be taken by someone. This result is also in line with Purnamasari (2015) who has found that perceived stress especially those related to "work stress aspect" and "stress no support aspect" to be significantly negatively correlated with the tendency of the department heads to lead again in the second period. Therefore, the researchers formulate the first hypotheses as follows:

H1: There is a significant effect of the LSE, PLE, OI, and PJSAL, on the AI-MTL of lecturers at the X University simultaneously.

\section{LSE as a mediator}

In addition, this study also wants to understand the role of LSE in mediating the relationship between Past Leadership Experiences (PLE) and AI-MTL and between Perceived Job Stress as an Academic Leader and AI-MTL. Basing their views on Bandura's theory, Amit et al. (2009) suggest that LSE mediates the relationship between past leadership experiences and AI-MTL. This is because past successful experiences are believed to increase someone's selfconfidence as a leader, which further increase his/her desire to take leadership positions (AIMTL). On the other hand, past leadership failure experiences are believed to reduce someone's self-confidence as a leader, which in turn will reduce the desire to take leadership roles (AI-MTL) in the future. Based on the explanations above, the researchers formulate the second hypotheses as follows:

H2: There is a significant effect of PLE on the X University lecturers' AI-MTL as mediated by LSE.

Besides, the researchers also suspect the role of LSE in mediating the relationship between Perceived Job Stress as an Academic Leader (PJSAL) and AI-MTL. From preliminary studies, the researchers found a tendency that if lecturers perceive leadership demands as threatening/inadequate with their competence (high perceived job stress), this will reduce their confidence as leaders, which further reduces their desire to lead. Conversely, when lecturers view leadership demands as not threatening/adequate with their competencies 
(low perceived job stress), this tends to increase their confidence as leaders, which in turn will increase their desire to lead. This is in line with Gangloff and Mazilescu (2017) who view that the feeling of doubt or uncertainty about capabilities (awareness of competence) can reduce self-efficacy, which in turn reduces performance. As for the organizational identification, the researchers do not hypothesize the role of LSE in mediating the relationship between organizational identification and AI-MTL. This is because the researchers argue that a strong identification with the organization does not necessarily have a positive effect on the confidence someone has to lead. Lecturers can have a strong identification with the organization even though they do not feel confident in leading. Accordingly, the researchers formulate the third hypotheses as follows:

H3: There is a significant effect of PJSAL on the X University lecturers' AI-MTL as mediated by LSE.

\section{METHOD}

Table 1.

Demographic Profiles of the Participants

\begin{tabular}{llcc}
\hline Demographic Characteristics & $n$ & $\%$ \\
\hline Gender & Female & 72 & 57.6 \\
& Male & 53 & 42.4 \\
\hline Age & $26-30$ years & 13 & 10.4 \\
& $31-40$ years & 47 & 37.6 \\
& $41-50$ years & 33 & 26.4 \\
& $51-60$ years & 24 & 19.2 \\
& $>$ 60 years & 8 & 6.4 \\
\hline Tenure & $1-5$ years & 46 & 36.8 \\
& 6-10 years & 16 & 12.8 \\
& $11-15$ years & 21 & 16.8 \\
& $16-20$ years & 9 & 7.2 \\
& $21-30$ years & 22 & 17.6 \\
& $>30$ years & 11 & 8.8 \\
\hline & Total & 125 & 100 \\
\hline
\end{tabular}

Table 1 shows the demographic profiles of participants. The population in this study were permanent lecturers at the $\mathrm{X}$ University who entitled to become leaders with the total number of 403. A formal cover letter to introduce the research was sent to the deans prior to the data collection period. The researchers then delivered the online questionnaire via google form to their personal network in all faculties, by using accidental sampling technique. From this data collection, as many as 125 people participated in this study. Most of the participants were female $(n=72,57.6 \%)$. The study participants were dominated by the group in the age range of 31-40 years $(n=47,37.6 \%)$ and the length of work between 1-5 years $(n=46,36.8 \%)$.

The process of data collection was conducted using five research instruments. The researchers first asked permission from the developers to translate their instruments from English into Indonesian. After that, a translation-back translation process was performed to ensure the suitability of the translation both grammatically and the study context. This process was implemented with the help of two experts in the field of psychology who were also fluent in English. Expert judgment was then carried out to evaluate the accuracy of meaning between the results of translation and back-translation by involving staff from the Language Teaching Center of the $\mathrm{X}$ University, which was followed by the try-out process.

The instruments used in this research were as follows:

(1) Affective Identity-Motivation to Lead (AI-MTL)

The AI-MTL instrument was developed by Chan and Drasgow (2001) to measure leadership motivation affectively. This questionnaire consisted of nine items that need to be responded by using a 5-point Likert scale format ranging from 1-Strongly Disagree to 5-Strongly Agree (Cronbach's $\alpha=$ .875). To clarify that the desired leadership context was in higher education, the researchers asked participants to imagine a campus situation where they worked together as a group or team (in the scope of study program/faculty/bureau/university). A sample 
item is 'I usually want to be the leader in the groups that I work with.'

\section{(2) Leadership Self-Efficacy (LSE)}

The LSE instrument was developed by Chan and Drasgow (2001) to measure a person's self-confidence regarding their leadership capabilities. This questionnaire consisted of six items that need to be responded by using a 5-point Likert scale format ranging from 1Strongly Disagree to 5-Strongly Agree (Cronbach's $\alpha=.850$ ). A sample item is 'I feel confident that I can be an effective leader in most of the groups that I work with.'

\section{(3) Past Leadership Experiences (PLE)}

The PLE instrument was developed by Chan and Drasgow (2001) to measure one's past leadership experiences, both quantitative and qualitative. Past leadership experiences were measured by using three items with several options. The answers were then quantified by giving a score ranging from 1 to 5 (Cronbach's $\alpha=.808$ ). A sample item is 'In your past experience working in groups and teams, how often did you become the leader?' A score of 1 would be given if the participant chose the 'Never' option, while a score of 5 would be given if the participant chose the 'Almost Always' option.

(4) Organizational identification (OI)

The OI instrument was developed by Mael and Ashforth (1992) to measure to what extent a person identified him/herself with the organization. This questionnaire consisted of six items that need to be responded by using a 5-point Likert scale format ranging from 1Strongly Disagree to 5-Strongly Agree (Cronbach's $\alpha=.828$ ). To make the items to be more relevant for the participants, the researchers used the word "X university" instead of "my organization." A sample item is 'This $X$ university's successes are my successes.'

(5) Perceived Job Stress as an Academic Leader (PJSAL)

Perceived job stress as an academic leader was intended to measure a person's perception of various work situations that had been identified as potential sources of stress for the academic leaders. Perceived job stress as an academic leader was measured by using the PJSAL instrument, where the items were modified from the Dean Stress Inventory to the context of academic leadership in general (Wild et al., 2003). This questionnaire consisted of 42 items that need to be responded by using a 5-point Likert scale format ranging from 1 indicated "Perceived Low Stress Level" to 5 indicated "Perceived High Stress Level” (Cronbach's $\alpha=.966$ ). Several sample items used in this instrument are: "Having insufficient time to stay current in my academic field" or "Feeling I have too heavy a workload, etc."

The data in this study then were analyzed using regression statistical technique. The use of regression in this study aimed to understand the effect of LSE, PLE, OI, and PJSAL, on AI-MTL of lecturers at the X University. The regression method chosen in this study was Hierarchical Multiple Regression. This method was chosen because it allowed researchers to determine the order of the variables entered the regression model based on the results of the previous studies (Field, 2013). Furthermore, Hayes' Process Macro for SPSS version 3.4 was employed to test the mediation effect of LSE in the relationship between PLE and AI-MTL, as well as between PJSAL and AI-MTL. Both analyses were performed using IBM SPSS version 22.

\section{RESULT AND DISCUSSION}

To understand the effect of LSE, PLE, OI, and PJSAL, on AI-MTL of lecturers at X University, a Hierarchical Multiple Regression analysis was carried out. All prerequisite tests were met before running the analysis. In this analysis, LSE was entered in Step 1, PLE was entered in Step 2, OI was entered in Step 3, and finally PJSAL was entered in Step 4. The results of One-Way Analysis of Variance (ANOVA) on the Step 4 show that the models can significantly predict AI-MTL, $F(4,120)=63.520, p<.001$. Thus, it can be concluded that there is a significant effect of LSE, PLE, OI, and PJSAL, on the 
AI-MTL of lecturers at the X University simultaneously. Therefore, $\mathrm{H} 1$ in this study is accepted. Table 2 describes the results of One-

Way Analysis of Variance of the AI-MTL.

Table 2.

One-Way Analysis of Variance of AI-MTL

\begin{tabular}{|c|c|c|c|c|c|}
\hline & $d f$ & $S S$ & $M S$ & $F$ & $p$ \\
\hline $\begin{array}{l}\text { Step } 1 \\
\text { Regression } \\
\text { Residual } \\
\text { Total }\end{array}$ & $\begin{array}{c}1 \\
123 \\
124\end{array}$ & $\begin{array}{c}3521.280 \\
2454.992\end{array}$ & $\begin{array}{r}3521.280 \\
19.959\end{array}$ & 176.423 & $.000^{* * * *}$ \\
\hline $\begin{array}{l}\text { Step } 2 \\
\text { Regression } \\
\text { Residual } \\
\text { Total }\end{array}$ & $\begin{array}{c}2 \\
122 \\
124 \\
\end{array}$ & $\begin{array}{c}3865.826 \\
2110.446\end{array}$ & $\begin{array}{r}1932.913 \\
17.299\end{array}$ & 111.737 & $.000^{* * * *}$ \\
\hline $\begin{array}{l}\text { Step } 3 \\
\text { Regression } \\
\text { Residual } \\
\text { Total }\end{array}$ & $\begin{array}{c}3 \\
121 \\
124\end{array}$ & $\begin{array}{c}4048.411 \\
1927.861\end{array}$ & $\begin{array}{r}1349.470 \\
15.933\end{array}$ & 84.698 & $.000^{* * * *}$ \\
\hline $\begin{array}{l}\text { Step } 4 \\
\text { Regression } \\
\text { Residual } \\
\text { Total }\end{array}$ & $\begin{array}{c}4 \\
120 \\
124\end{array}$ & $\begin{array}{l}4059.171 \\
1917.101\end{array}$ & $\begin{array}{r}1014.793 \\
15.976\end{array}$ & 63.520 & $.000^{* * * *}$ \\
\hline
\end{tabular}

Table 3.

Regression Coefficient of Variables that Predict AI-MTL

\begin{tabular}{lcccccc}
\hline Variable & $b$ & $b^{*}$ & $t$ & $R^{2}$ & $\Delta R^{2}$ & $F$ for change $R^{2}$ \\
\hline Step 1 & & & & & & \\
LSE & 1.400 & .768 & $13.282^{* * *}$ & .589 & .589 & 176.423 \\
\hline Step 2 & & & & & & \\
LSE & 1.037 & .568 & $8.126^{* * *}$ & .647 & .058 & 19.917 \\
PLE & 1.051 & .312 & $4.463^{* * *}$ & & & \\
\hline Step 3 & & & & & & \\
LSE & .985 & .540 & $7.980^{* * *}$ & .677 & .03 & 11.460 \\
PLE & .956 & .284 & $4.197^{* * * *}$ & & & \\
OI & .262 & .182 & $3.385^{* *}$ & & & \\
Step 4 & & & & & & \\
LSE & .941 & .516 & $7.004^{* * *}$ & .679 & .002 & .674 \\
PLE & .975 & .290 & $4.254^{* * *}$ & & & \\
OI & .259 & .180 & $3.338^{* * *}$ & & & \\
PJSAL & -.010 & -.047 & -.821 & & & \\
\hline
\end{tabular}

Note. $N=125$.

${ }^{* *} p<.01 .{ }^{* * *} p<.001$.

Table 3 describes the regression coefficient of variables that Predict AI-MTL. It is necessary to look at the contribution of each variable entered into the model starting from the Step 1 to Step 4. The results of the Hierarchical
Multiple Regression show that in Step 1, LSE has a significant effect on AI-MTL, $F(1,123)$ $=176.423, p<.001$, and is able to explain $58.9 \%$ of the AI-MTL variation, $R^{2}=.589$. The addition of PLE in Step 2 is able to 
provide an additional contribution of $5.8 \%$ of the AI-MTL variation, $\Delta R^{2}=.058, F(1,122)$ $=19.917, p<.001$. The addition of OI in Step 3 is able to provide an additional contribution of $3 \%$ of the AI-MTL variation, $\Delta R^{2}=.03$, $F(1,121)=11.460, p<.01$. The addition of PJSAL in Step 4 does not provide any additional significant contribution to the variation of AI-MTL, $\Delta R^{2}=.002, F(1,120)=$ $.674, p>.05$. Thus, all the variables are able simultaneously to explain $67.9 \%$ of the AIMTL variation with LSE as the most important predictor.

To understand the role of LSE in mediating the relationship between PLE and AI-MTL, the stages of mediation testing according to Baron and Kenny (1986) need to be examined.
In Step 1 of the mediation stages, PLE, ignoring the mediator, significantly predicts AI-MTL, $c=2.2730, p<.001$. Step 2 showed that the PLE significantly predicts LSE as the mediator, $a=1.1791, p<.001$. Step 3 of the mediation stages showed that the mediator (LSE) significantly predicts AI-MTL, $b=$ $1.0365, p<.001$. Step 4 of the analysis revealed that the relationship between PLE and AI-MTL became smaller with the inclusion of LSE as the mediator, $c^{\prime}=1.0508$, $p<.001$ (compared with $c=2.2730, p<.001$ ). Thus, in this relationship exists what is known as partial mediation (see Picture 1). Therefore, $\mathrm{H} 2$ in this study is accepted, i.e., there is an effect of PLE on the AI-MTL which is partially mediated by LSE.

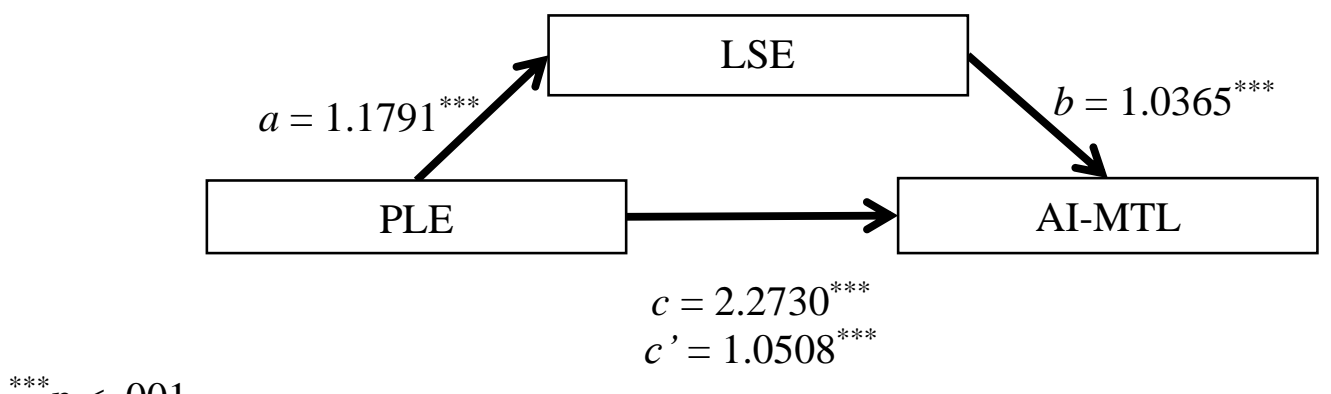

${ }^{* * * *} p<.001$

Figure 1. LSE Mediation Effect on The Relationship Between PLE and AI-MTL

The stages of mediation testing according to Baron and Kenny (1986) are then reused to see the role of LSE in mediating the relationship between PJSAL and AI-MTL. In Step 1 of the mediation stages, PJSAL, ignoring the mediator, significantly predicts AI-MTL, $c=-.073, p<.001$. Step 2 showed that the PJSAL significantly predicts LSE as the mediator, $a=-.049, p<.001$. Step 3 of the mediation stages showed that the mediator (LSE) significantly predicts AI-MTL, $b=$
1.376, $p<.001$. Step 4 of the analysis revealed that the relationship between PJSAL and AI-MTL became no longer statistically significant with the inclusion of LSE as the mediator, $c^{\prime}=-.006, p>.05$ (compared with $c$ $=-.073, p<.001)$. Thus, full mediation occurs in this relationship (see Picture 2). Therefore, $\mathrm{H} 3$ in this study is accepted, i.e., there is an effect of PJSAL on the AI-MTL which is fully mediated by LSE.

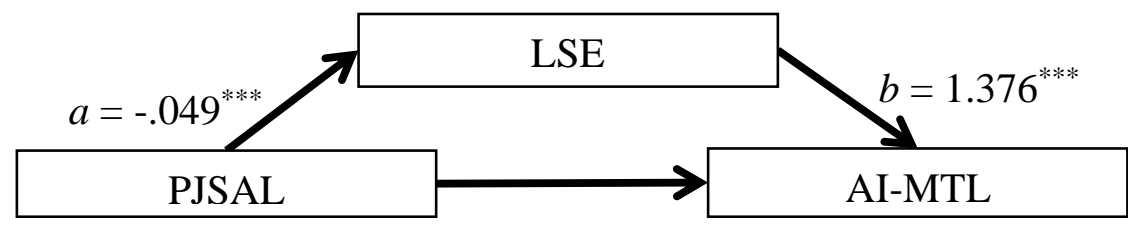

$$
\begin{gathered}
c=-.073^{* * *} \\
c^{\prime}=-.006
\end{gathered}
$$

${ }^{* * *} p<.001$

Figure 2. LSE Mediation Effect on The Relationship Between PJSAL and AI-MTL 
This study aims to identify the effect of Leadership Self-Efficacy (LSE), Past Leadership Experiences (PLE), Organizational Identification (OI), and Perceived Job Stress as an Academic Leader (PJSAL) on the AI-MTL of lecturers at the X University. In addition, this study also aims to understand how LSE mediates the relationship between Past Leadership Experiences (PLE) and AI-MTL and between Perceived Job Stress as an Academic Leader (PJSAL) and AI-MTL.

The result shows that LSE, past leadership experiences, organizational identification, and perceived job stress as an academic leader, simultaneously affect AI-MTL of lecturers at the X University and can explain $67.9 \%$ of the AI-MTL variation. LSE is the most important predictor, capable in explaining $58.9 \%$ of AIMTL variations, followed by past leadership experiences and organizational identification. Meanwhile, perceived job stress as an academic leader does not provide any meaningful contribution to the variation of AI-MTL. The result of mediation testing further find the role of LSE in partially mediating the relationship between past leadership experiences and AI-MTL. Besides that, LSE is also found to fully mediating the relationship between perceived job stress as an academic leader and AI-MTL.

The role of LSE as the most important variable for predicting AI-MTL in the context of higher education is confirmed in this study, in line with previous findings (Chan \& Drasgow, 2001; Mascia et al., 2014). Lecturers' belief in their leadership capacity tend to make them want to pursue a career in the field they are good at. In addition, this selfconfidence will make them feel capable in dealing with the difficulties that may be caused by their leadership position (Bandura, 2006, as cited in Rehm \& Selznick, 2019). This further increases their motivation to pursue various leadership roles (Mascia et al., 2014).

The results of the analysis show the important role of past leadership experiences in predicting AI-MTL of lecturers at the $\mathrm{X}$ University and the role of LSE in mediating the relationship between the two. It means that the relationship can be both direct and indirect in line with the research results of Chan and Drasgow (2001). Past leadership experiences can have a direct effect on AI-MTL because those experiences may help lecturers to internalize themselves with the leadership roles, which then motivate them to lead (Amit et al., 2009). Besides, past leadership experiences can affect the improvement of AIMTL by strengthening LSE. The lecturers' feeling of success while leading previously tends to strengthen self-confidence in their leadership abilities, which then increases their motivation to lead (Bandura, 1986, as cited in Amit et al., 2009). Past leadership experiences can also strengthen LSE because these experiences help lecturers to understand how they should manage their future leadership responsibilities (St. Marthe, 2012).

The contribution of organizational identification in predicting AI-MTL for lecturers at the $\mathrm{X}$ University is also an important finding of this study. Organizational identification described as to what extent someone identifies him/herself toward the organization and considered the success and failure of the organization as his/her success and failure (Mael \& Ashforth, 1992), is found by Fritz and van Knippenberg (2017) to also affect leadership aspirations. This is because organizational identification can also be linked with the motivation to behave in ways that are beneficial for the organization (Fritz \& van Knippenberg, 2017). Therefore, if there is a vacant leadership position, lecturers with high identification toward the organization tend to be more motivated to fill that position to help the organization achieve its goals. Therefore, they use the perspective of the organization as their perspective, which is then used to take the best action for the needs of the organization (van Knippenberg \& van Schie, 2000, as cited in Tsui \& Ngo, 2015).

The study results have further indicated that perceived job stress as an academic leader do 
not provide a meaningful contribution in predicting AI-MTL, because the relationship with AI-MTL is fully mediated by LSE. The addition of LSE to the mediation testing results in the role of perceived job stress as an academic leader to be no longer significant in predicting AI-MTL, in which previously significant. In the context of the X University, perceived job stress as an academic leader does not directly reduce the desire of lecturers to serve, as previously found by Purnamasari (2015), but this relationship is fully mediated by LSE. It means that lecturers' perception that leadership responsibilities are stressful tend to weaken their confidence in their leadership abilities first, which in turn make them less motivated to lead. This can be explained by referring to the opinion of Gangloff and Mazilescu (2017) although not directly related to LSE. According to them, persons' uncertainty/doubt about whether they may be able to handle something or not (awareness of competence) tends to reduce self-efficacy which then affects their motivation to behave. This argument can be considered valid in helping to explain the results of this finding.

The main limitation of this study lies in collecting data from one of the traditional universities in Jakarta. Thus, the results of this study can only be generalized to other universities that have the same characteristics. The choice of traditional universities is not without reason. The researchers find that the challenges of managing traditional universities are often perceived as more complex than those of modern universities, thus making leadership positions less attractive to lecturers. Leaders in traditional universities on the one hand are required to be able to reform their organizations to be more effective, efficient, and better able to answer the needs of stakeholders, through the implementation of "New Public Management" (Broucker \& De Wit, 2015). On the other hand, they are also required to be able to face the reluctance of the academic community who think that the reform will lead to the liberalization of education
(Mainardes et al., 2011). This kind of thing is generally no longer a problem in modern universities, which have been equipped with good management systems since their establishment.

For the future studies, the researchers suggest considering extroversion as a variable that needs to be included to predict AI-MTL. This is because extroversion has been known as a predictor of emerging leadership (Zaccaro et al., 2018). People who have various extroverted characteristics (such as assertiveness, boldness, and talkativeness) tend to be perceived by their peers as leaders (Do \& Minbashian, 2014, as cited in Spark \& O'Connor, 2021), so extraversion is believed to affect AI-MTL too. In addition, the researchers also suggest examining two other components of Motivation-to-Lead that have not been measured in this study, namely Social Normative-Motivation to Lead (SNMTL) and Noncalculative-Motivation to Lead (NC-MTL). This is because the two motivations are also considered influential in motivating lecturers to take leadership roles in universities. The study results of DeZure et al. (2014) for example, which see leadership as a form of dedication to the organization, is closely related too with these two components.

Based on the results of this study, the researchers can provide several suggestions as the practical implication of this study:

1) It is very important to look at LSE as well as past leadership experiences when recruiting lecturers. These may become an additional profiling data that can be very useful in identifying potential candidates when there is a need for leadership position. This can be implemented by using various assessment methods such as Behavioral Event Interview (BEI), psychological testing, references, and so on.

2) There is a necessity for the development of various programs both for succession planning (such as through training programs, mentoring, on-the-job training, etc.) and for 
strengthening lecturer support systems whilst in serving (such as administrative system, information technology system, etc.). By providing this, lecturers can have a better perception about the roles and duties as the leaders that may potentially increase their motivation to lead. In addition, providing support systems are also expected to be able to increase lecturers' organizational identification through the support perceived when being in office.

3) There is a necessity to require leadership experiences at a lower level as a prerequisite for appointment at the next level (for example: appointment at the dean level requires a lecturer to have served as head of a study program, etc.). This is expected to increase the lecturers' motivation to pursue higher positions due to the feeling of being capable when handling leadership tasks at the lower positions.

4) There is a necessity to build a positive perception regarding the role of leadership in universities. For example, this can be implemented by sharing positive experiences when being in a leadership position that hopefully may be able to correct / minimize negative perceptions towards this role. This is because after all the leadership positions in higher education must be filled by lecturers although these positions are more of an additional job in nature.

\section{CONCLUSION}

The study shows that there is a significant effect of LSE, past leadership experiences, organizational identification, and perceived job stress as an academic leader, simultaneously on AI-MTL of lecturers at the $\mathrm{X}$ University. LSE is the most important predictor, capable in explaining more than $50 \%$ of AI-MTL variations, followed by past leadership experiences, and organizational identification. In addition, the result also shows the role of LSE in partially mediating the relationship between past leadership experiences and AI-MTL, as well as fully mediating the relationship between perceived job stress as an academic leader and AI-MTL. Thus, it is important for the universities to consider these factors when looking for potential leaders. Further, this implementation is expected to help universities with a similar problem to overcome the difficulties experienced in finding their prospective leaders.

\section{ETHICAL CLEARANCE}

This research project has received Ethical Clearance approval from the Atma Jaya Catholic University of Indonesia Research Ethics Commission (No: 1781/III/LPPMPM.10.05/02/2019).

\section{REFERENCES}

Amit, K., Popper, M., Gal, R., Mamane-Levy, T., \& Lisak, A. (2009). Leadershipshaping experiences: A comparative study of leaders and non-leaders. Leadership \& Organization Development Journal, 30(4), 302-318. https://doi.org/10.1108/01437730910961 $\underline{658}$

Badura, K. L., Grijalva, E., Galvin, B. M., Owens, B. P., \& Joseph, D. L. (2020). Motivation to lead: A meta-analysis and distal-proximal model of motivation and leadership. Journal of Applied Psychology, 105(4), 331-354. http://dx.doi.org/10.1037/ap10000439

Baron, R. M., \& Kenny, D. A. (1986). The moderator-mediator variable distinction in social psychological research: Conceptual, strategic, and statistical considerations. Journal of Personality and Social Psychology, 51(6), 1173-1182. https://doi.org/10.1037/0022$\underline{3514.51 .6 .1173}$

Bergner, S., Kanape, A., \& Rybnicek, R. (2018). Taking an interest in taking the lead: The influence of vocational interests, leadership experience and success on the 
motivation to lead. Applied Psychology: An International Review, 68(1), 202-219. https://doi.org/10.1111/apps.12150

Broucker, B., \& De Wit, K. (2015). New public management in higher education. In J. Huisman et al. (Eds.), The Palgrave International Handbook of Higher Education Policy and Governance (pp. 57-75). Palgrave Macmillan. https://doi.org/10.1007/978-1-13745617-5

Chan, K. Y., \& Drasgow, F. (2001). Toward a theory of individual differences and leadership: Understanding the motivation to lead. Journal of Applied Psychology, $86(3)$, 481-498.

https://doi.org/10.1037/0021$\underline{9010.86 .3 .481}$

Chan, K. Y., Ho, M. R., \& Sam, Y. L. (2013, May 22-25). Affective, non-calculative and social motivation to lead: What we know from studies of entrepreneurial, professional \& leadership motivation [Conference session]. The $16^{\text {th }}$ Congress of the European Association of Work and Organizational (EAWOP), Münster, Germany. https://doi.org/10.13140/2.1.1799.5529

Chen, L. (2016). Linking leader personality traits to motivation to lead: A self-concept approach. Social Behavior and Personality, 44(11), 1913-1926. http://dx.doi.org/10.2224/sbp.2016.44.11. 1913

DeZure, D., Shaw, A., \& Rojewski, J. (2014). Cultivating the next generation of academic leaders: Implications for administrators and faculty. Change: The Magazine of Higher Learning, 46(1), 612.

https://doi.org/10.1080/00091383.2013.8 $\underline{42102}$

Field, A. (2013). Discovering Statistics Using IBM SPSS Statistics (4 th $^{\text {Ed. }}$ ). Sage Publication Ltd.
Fritz, C., \& van Knippenberg, D. (2017). Gender and leadership aspiration: The impact of organizational identification. Leadership \& Organization Development Journal, 38(8), $\quad 1018$ -

1037. https://doi.org/10.1108/LODJ-05$\underline{\text { 2016-0120 }}$

Gangloff, B., \& Mazilescu, C. (2017). Normative Characteristics of Perceived Self-Efficacy. Social Science, 6(4), 139, 1-18.

https://doi.org/10.3390/socsci6040139

Gmelch, W. (2015). The call for leadership: Why chairs serve, what they do, and how long they should serve. $A K A$ Monographs: Leading and Managing the Kinesiology Department, 1(1), 1-12. https://americankinesiology.org/Content/ Documents/01_Gmelch_mono_series.pdf

Guillen, L., Mayo, M., \& Korotov, K. (2015). Is leadership a part of me? A leader identity approach to understanding the motivation to lead. The Leadership Quarterly, 26(5), 802-820. http://dx.doi.org/10.1016/j.leaqua.2015.0 5.001

Loomes, S., Owens, A., \& McCarthy, G. (2019). Patterns of recruitment of academic leaders to Australian universities and implications for the future of higher education. Journal of Higher Education Policy and Management, 41(2), 137-152. https://doi.org/10.1080/1360080X.2019.1 565296

Luna, G. (2012). Planning for an American higher education leadership crisis: The succession issue for administrators. International Leadership Journal, 4(1), 56-79.

http://citeseerx.ist.psu.edu/viewdoc/down load?doi=10.1.1.464.5025\&rep=rep1\&ty pe $=$ pdf\#page $=57$

Mael, F. A., \& Ashforth, B. E. (1992). Alumni and their alma mater: A partial test of a 
reformulated model of organizational identification. Journal of Organizational Behaviour, 13(2), 103-123. https://doi.org/10.1002/job.4030130202

Magrane, D., Morahan, P. S., Ambrose, S., \& Dannels, S. A. (2018). Competencies and practices in academic engineering leadership development: Lessons from a national survey. Social Sciences, 7(10), 113.

https://doi.org/10.3390/socsci7100171

Mainardes, E. W., Alves, H., \& Raposo, M. (2011). The process of change in university management: From the "ivory tower" to entrepreneurialism. Transylvanian Review of Administrative Sciences, $\quad 7(33), \quad$ 124-149. https://rtsa.ro/tras/index.php/tras/article/v iew/287/280

Mascia, D., Russo, S. D., \& Morandi, F. (2014). Exploring professionals' motivation to lead: A cross-level study in the healthcare sector. International Journal of Human Resource Management, 26(12), $1622-1644$ https://doi.org/10.1080/09585192.2014.9 $\underline{58516}$

Murphy, S. E., \& Johnson, S. K. (2016). Leadership and leader developmental selfefficacy: Their role in enhancing leader development efforts. New Directions for Student Leadership, 149, 73-84. https://doi.org/10.1002/yd.20163

Peraturan Perusahaan Yayasan $X \quad[X$ Foundation Company Regulation]. (2019). Yayasan X

Porter, T., Riesenmy, K., \& Fields, D. (2016). Work environment and employee motivation to lead. American Journal of Business, $\quad 31(2), \quad 66-$ 84. https://doi.org/10.1108/AJB-05-2015$\underline{0017}$

Purnamasari, A.V. (2015). Beyond tenured: Analysis of the influence of department chair role conflict, stress, job satisfaction and their likelihood to serve for another term [Doctoral dissertation, Iowa State University]. Iowa State University Digital Repository.

https://lib.dr.iastate.edu/etd/14615

Rehm, C., \& Selznick, B. S. (2019). Measuring leader self-efficacy among youth. The Journal of Leadership Education, 18(2), 52-61. https://doi.org/10.12806/V18/I2/R4

Spark, A., \& O’Connor, P. J. (2021). State extraversion and emergent leadership: Do introverts emerge as leaders when they act like extraverts? The Leadership Quarterly, 32(3), 101474. https://doi.org/10.1016/j.leaqua.2020.101 474

Stiehl, K. S., Felfe, J., Elprana, G., \& Gatzka, M. B. (2015). The role of motivation to lead for leadership training effectiveness. International Journal of Training and Development, $\quad 19(2), \quad 81-97$. https://doi.org/10.1111/ijtd.12051

St. Marthe, T. M. (2012). Female academic department chairs at a public, very high research activity university: Exploring their career pathways to success [Doctoral Dissertation, University of Arkansas]._ScholarWorks@UARK. http://scholarworks.uark.edu/etd/658

Tsui, P. Y., \& Ngo, Hang-Yue. (2015). A study of organizational identification of faculty members in Hong Kong business schools. Journal of Education for Business, $\quad 90(8), \quad$ 427-434. https://doi.org/10.1080/08832323.2015.1 $\underline{087372}$

Waggoner, R. (2016). Pipelines to leadership: Aspirations of executive-level community college leaders to ascend to the presidency [Doctoral dissertation, University of Kentucky]. UKnowledge. http://dx.doi.org/10.13023/ETD.2016.139 
Wild, L. L., Ebbers, L. H., Shelley, M. C., \& Gmelch, W. H. (2003). Stress factors and community college deans: The stresses of their role identified. Community College Review, $31(3)$ $1-$ 23. https://doi.org/10.1177/00915521030 $\underline{3100301}$
Zaccaro, S. J., Green, J. P., Dubrow, S., \& Kolze, M. (2018). Leader individual differences, situational parameters, and leadership outcomes: A comprehensive review and integration. The Leadership Quarterly, 29(1), 2-43. https://doi.org/10.1016/j.leaqua.2017.10. $\underline{003}$ 